\section{Portable pH Meter}

The new PH M 230 pH meter from Dostmann electronic $\mathrm{Gm}$ $\mathrm{bH}$ measures the $\mathrm{pH}$ value, the reduction potential and the temperature in different media. Special $\mathrm{pH}$ electrodes extend the application of the meter to non-liquid foods. The meter offers a wide variety of application possibilities. It has a data logger for automatic recording of the measured values. The mains adapter reduces the costs of the power supply in stationary laboratory operation. The PH M 230 measures the temperature and, if an external $\mathrm{pH}$ electrode is connected, it also measures the $\mathrm{pH}$ value as well as the reduction potential when a redox probe is connected. The measuring range of the $\mathrm{pH}$ value is from 0.00 to 14.00 , for temperature from 0.0 to $60.0^{\circ} \mathrm{C}$ and for the reduction potential from -1999 to $+1999 \mathrm{mV}$. The measuring interval can be freely selected between 1 second and almost 9 hours. The $\mathrm{pH}$ value is shown on a large twoline LC display with a resolution of $0.01 \mathrm{pH}$ units and the temperature is displayed with a resolution of 0.1 ${ }^{\circ} \mathrm{C}$. The Min/Max function records the minimum and maximum values while the Hold function makes reading the measured value more convenient. The date and time can also be archived to provide comprehensive documentation. Data can be exported via an SD card (not included), which can be inserted into the card reader of a PC or laptop computer.

The values can then be directly recalled and processed in Excel.

Tel. +499342 308-90, www. dostmannelectronic.de

\section{New Colour Display for Coating Thickness}

\section{Measurement}

The handheld coating thickness meters of the FMP10-40 series from Fischer allow non-destructive coating thickness measurement using the magnetic induction and/or eddy current process as well as measurement of the ferrite content in austenite and duplex steels. Equipped with a new high-contrast colour display, which is specially protected against dust and other soiling, these user-friendly and sturdy meters are ideally suited for measuring corrosion protection coatings on steel and aluminium in aggressive environments. The meters already have stored specifications for measurements according to IMO PSPC and SSPC PA2. The large and varied selection of wear-resistant measuring probes for many different requirements can precisely measure coating thicknesses even on rough surfaces. The meters are easy to use and have a USB interface for transferring the measured values to a PC, where they can be evaluated, logged and archived with the user-friendly and intuitive software. This makes it possible to create individual test reports.

mail@helmut-fischer.de, www.helmut-fischer.de

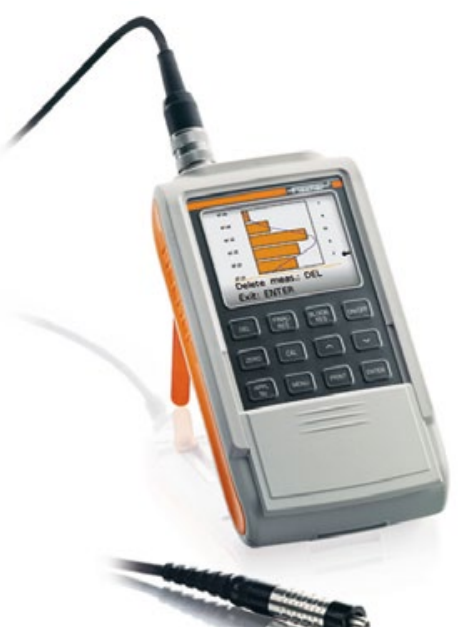

\title{
User-Friendly Coating Thickness Gauge for Many Fields of Application
}

$T^{\text {he }}$ he convenient Layercheck 750 USB thickness gauge from Erichsen is used for quick and precise, non-destructive coating thickness measurements on metallic substrates. Typical fields of application include industrial corrosion protection, electroplating and paint shops and the chemical, automotive and mechanical engineering industries. Its rubber surround provides additional impact protection. It is held in place by a spring-mounted sleeve. This ensures safe and stable positioning of the probe as well as a constant contact pressure. The single-pole measuring probe is connected to the gauge via a cable (1 metre long). The coating thickness gauge is equipped with a large, backlit LC display for measurements in badly lit surroundings. Depending on the type of instrument and probe, the coating thickness gauges work either accord- ing to the magnetic induction principle (model 750 USB-F) or the eddycurrent method (model 750 USB-FN). Tel. +49 2372 9683-0, www.erichsen.de

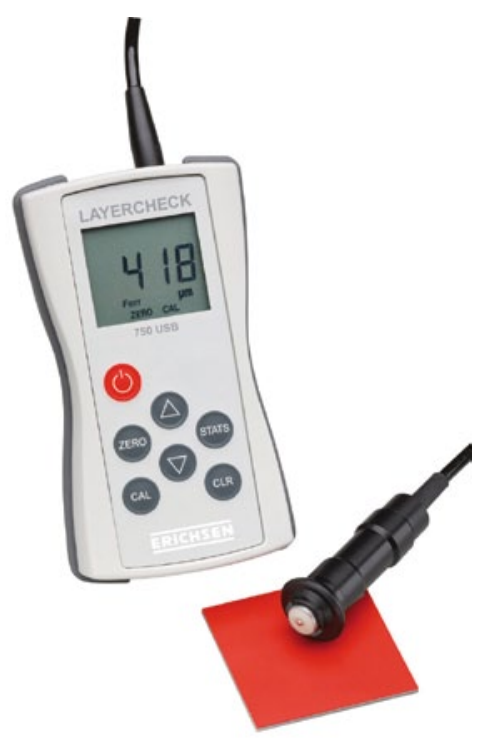

